\title{
Lagar e torcular na diplomática medieval latina de Galicia
}

\author{
Xaime Varela Sieiro
}

\section{AS ORIXES}

1.1. Na orixe de lagare está o substantivo masculino lacus,-us na súa acepción de 'estanque', 'depósito de un líquido'. Este vocábulo, xa nos primeiros tempos da lingua, aludía especialmente a un recipiente para almacenar o viño ou mesmo a unha especie de lagar; cf. CATO, agr. 25, conculcato in dolia picata uel in lacum uinarium picatum; VARRO, rust. 1, 13, 6, cellam uinariam et oleariam... pauimento procliui in lacum; 1, 54, 2, siquid reliqui habeant folliculi uuae musti, exprimatur in eumdem lacum. Máis tardiamente en ColvM. 12, 19, 3, mustum... de lacu in uasa defrutaria deferemus, ou en Isidoro, etym. 15, 6, 8, lacus dictus, quia ibi decurrit frugum (uuarum var. 1) liquor; 20, 14, 12, lacus quo liquatus profluat, quo ab uuis uel oliuis torquendo oleum uinumque exigitur. En efecto, anque de xeito fundamental se relacionaba coa elaboración do viño, tamén podería cumprir a mesma función na do aceite se ben os exemplos son máis escasos, entre eles, CATO, agr. 66, 1, cortinam plumbeam in lacum ponito, quo oleum fluat (ThLL, s. v. lacus).

Daquela lagar sería un termo formado sobre lacus na acepción de 'depósito de líquidos, sobre todo, de viño' máis o sufixo -ar(e), que quizais achegue un valor locativo. Machado, s. v. lagar, supón que debe estar emparentado, en efecto, con lago, mais dubida entre unha formación románica e a representación dun latín *lacale, idea pola que finalmente se inclina. Na nosa opinión, todo parece indicar que lagar é unha construcción románica, análoga á do seu sinónimo torcular, formada cun sufixo indicador de lugar. 
1.2. Do substantivo latino torculum 'prensa de viño ou aceite' $<$ torqueo 'retorcer', proceden outros dous de igual significado e utilización dende a antiguidade latina: co sufixo -ar(e), torcular, -aris (neutro dun adxectivo *torcularis); e co sufixo -arium, torcularium (Ernout-Meillet, s. v. torqueo). En virtude dos exemplos que nos fornecen os diccionarios ó uso semella que foi máis corrente torcular; en calquera caso, ambos os dous significan 'edificio onde está a prensa' e 'a propia prensa' tanto para o viño coma para o aceite. Velaquí algúns exemplos, VITR. 6, 6, 2, Torcular proximum sit culinae; PLIN. 15, 2, Distat, an maturitas illa (oleae) in torcularibus fiat an ramis ou CATO. agr. 12, 1, in torcularium quae opus sint (Forcellini, s. v. torcular e torcularium). E, por suposto, Isidoro tamén nos ofrece a súa propia explicación desta voz en etym. 15, 6, 7, Torcular dictum eo quod ibi uuae calcentur atque extortae exprimantur.

Por outra banda, a Vulgata constitúe un testemuño interesante para comprobar que Xerome, na súa época, decidiuse pola forma torcular fronte a lacus: cf. ITALA deut. 16, 13, dum colliges ab area tua et a lacu tuo (VvLG. torculari); Matth. 21,33, plantauit uineam...et fodit in ea lacum (VVLG. torcular).

\section{USO E FRECUENCIA}

2.1. Dende finais do século IX ata o 1250 , podemos contabilizar no noso ámbito documental ${ }^{1}$ ó redor dunha centena de documentos, isto é, un $2,2 \%$ da totalidade, nos que alomenos se rexistra unha vez o termo la-

1 O noso conxunto documental intégrano 4200 documentos de 37 entidades relixiosas do actual espacio administrativo de Galicia, datados entre o século VIII e o ano 1250 e que figuran xa editados. Para citar os documentos do noso corpus seguimos o procedemento seguinte: unha abreviación da entidade relixiosa da que procede a devandita acta, o número de documento na edición manexada e, por último, a data da carta. Un asterisco antecedendo a esta referencia indicará que é un doc. orixinal. Pola contra, cando citemos paralelamente datos doutros corpus documentais, que tiramos da nosa investigación no Arquivo do Comité Du Cange, utilizaremos o sistema e as abreviaturas empregados na redacción do Novum glossarium mediae latinitais ab anno DCCC usque ad annum MCC, Copenhague, 1957-. 
gar ou unha das súas variantes. A nosa primeira mención é Ce. 342, $885^{2}$, ipsa colina medietate et de ipso lagare...; mais un pouco antes xa se rexistra nunha acta auténtica asturleonesa, no a. 870, terras ruptas uel barbaras, casas, lacar, petras mouiles et inmobiles ${ }^{3}$; este testemuño sería, por tanto, o máis antigo que posuímos da voz lagar.

Unha boa parte das nosas actas, un $65 \%$, son orixinais debido a que esta voz se documenta tardiamente, sobre todo, durante o século XIII; o orixinal máis antigo no noso corpus é *Me. $8,1203^{4}$, medietate uini in lagare. É un termo común a moitas das nosas coleccións documentais anque destaca a súa ausencia no tombo de Sobrado así como a escasa presencia no de Samos. Por outra banda, cómpre sinalar que é coñecido en toda a documentación latina do Noroeste peninsular pero non noutros ámbitos, co cal, e segundo os nosos coñecementos, podemos afirmar que é un hispanismo cunha forte implantación no cadrante noroccidental ${ }^{5}$.

Cronoloxicamente, os diplomas concernentes a lagar localízanse en dúas épocas diferentes:

a) entre o 950 e o 1050 datan o $27 \%$ dos documentos analizados ${ }^{6}$.

2 Vid. J. M. Andrade (1995).

3 Vid. P. Rodríguez Fernández (1983: 707).

4 Vid. M. T. Soto Lamas (1992).

5 Cf. CARTUL. S. Jacob. Legion. p. 137, a. 917, cum corte sicut est conclusa, cum suas kasas, terras, uineas, pratis, padulibus, molinos tres, montes, fontes et suo lagare...; Doc. cath. Ovet. p. 101, a. 951, tam de parentorum quam etiam de comparado qui in scripturas resonant... siue kasas, cupas, lagare; CARTUL. S. Vinc. Ovet. p. 55, a. 974, per illum salice et solare de illo lacare qui fuit de... et per illum cippum de illa castaniare tras illum furnum ou Doc. reg. Port. I, p. 155, a. 1133, et inde per illam uallem et per illam carralem usque in illum lagarem.

6 - A escaseza de mencións neste período queda patente noutros traballos sobre estas voces: M. P. Álvarez Maurín (1994: 298), tan só nos ofrece exemplos en catro actas que datan entre o s. IX e finais do XI; P. Rodríguez Fernández (1983: 707-708), malia a abranguer a documentación asturleonesa entre os século VIII e XIII, fornece exemplos tan só en nove actas datadas entre o 870 e o 1086. 
b) entre o 1200 e o 1250 un $65 \%$. Esta alta porcentaxe explícase por ser lagar un termo presente en fórmulas propias dos contratos forais, típicos deste período.

Agora ben, a porcentaxe de utilización con respecto ó número total de documentos contabilizados para cada período, reflicte que a primeira metade do XI, proporcionalmente, é a época de maior utilización; a partir de aquí cae o seu uso, incluso chegamos a non documentalo na segunda metade do XII. O rexurdir deste termo acontece no XIII e, como veremos, mercede ó seu emprego formular en documentos forais.

\begin{tabular}{|c|c|}
\hline Cronoloxía & Total: $2,2 \%$ \\
\hline $850-899$ & $2 \%$ \\
\hline $900-949$ & $0,55 \%$ \\
\hline $950-999$ & $3,5 \%$ \\
\hline $1000-1049$ & $5,9 \%$ \\
\hline $1050-1099$ & $1,6 \%$ \\
\hline $1100-1149$ & $0,5 \%$ \\
\hline $1150-1199$ & - \\
\hline $1200-1250$ & $4,07 \%$ \\
\hline
\end{tabular}

2.2. O documento máis antigo do noso corpus no que figura torcular data de mediados do IX ${ }^{7}$, uns trinta anos antes có primeiro que contén lagar, en Sa. 99, 854 , Construximus ecclesiam ipsam in amorem Dei omnipotentis et casas, cellarium et quoquinam seu et torcular. E ó igual que ocorría con lagar, está practicamente ausente dun Tombo tan importante coma o de Sobrado dos Monxes; en cambio, en Samos hai un notable incremento. Con todo segue a ser no tombo de Celano-

7 En DEPA xa se rexistra un do ano 800, domicilia, cellarios, orreos, torcularibus (Rodríguez Fernández 1983: 712).

8 Vid. M. Lucas Álvarez (1986). 
va onde se reproduce de xeito máis xeral. Polo que respecta a outras coleccións documentais, é unha voz común e estendida nas actas medievais ${ }^{9}$.

En canto á frecuencia de uso, é similar, aínda que torcular franquea con claridade a barreira do centenar de documentos (contamos 114), o que supón un $2,7 \%$ do total de documentos, deles só un 34\% son orixinais, o máis antigo *Sa. S17, 1074, uilla cum intrinsecus suis, domus, kasas, torculares, cupas, cupos,... De xeito análogo ó que sucedía con lagar, os documentos que ofrecen o termo tocular pódense agrupar en dous períodos, agora ben, a porcentaxe de utilización é inversa, como vemos no cadro de abaixo, debido a unha serie de condicionantes que logo analizaremos:

\begin{tabular}{|l|c|c|}
\hline & séculos X-XI & século XIII \\
\hline lagar & $31,2 \%$ & $65,6 \%$ \\
\hline torcular & $58 \%$ & $37,5 \%$ \\
\hline
\end{tabular}

De compararmos a porcentaxe de documentos que conteñen un e outro termo con respecto á totalidade da documentación que posuímos para cada período, obtemos os seguintes datos:

9 Cf. na Península, LiB. fid. Brac. I, p. 210, a. 1027, casas et uineas, labores, cortinas, torcular, fructeiras et aquas cursiles; Doc. cath. Ovet. p. 28, a. 857, cum domibus, orreis, torcularibus et cum quattuor paribus bouum; CARTUL. Irach. p. 33, a. 1063, de eadem domum... una cum suo solare et torculare que est supra domum et cum terris et uineis; Doc. Sanc. Maior. app. III, p. 120, a. 1027, una uinea... et suo torculare ou CARTUL. Popul. p. 146, 1196, donec fratres predicti monasterii in area uel torculari...; Fóra da Península tamén encontramos numerosos exemplos como CARTUL. Carcas. I, p. 80, a. 1011, ad Autarium ... et torcular; CARTUL. dom. Nigell. p. 132-33, a. 1172, nemo aliud ibi torcular possit edificare; CARTUL. Remens. p. 123, a. 1100, apud uillam dominicam et torcular unum ou CARTUL. S. Marg. Med. p. 36, a. 1182, et facere uinum ad torcular. 


\begin{tabular}{|c|c|c|}
\hline Cronoloxía & Total lagar: $2,2 \%$ & Total torcular: $2,7 \%$ \\
\hline $850-899$ & $2 \%$ & $4,1 \%$ \\
\hline $900-949$ & $0,55 \%$ & $1,6 \%$ \\
\hline $950-999$ & $3,5 \%$ & $4,2 \%$ \\
\hline $1000-1049$ & $5,9 \%$ & $12,9 \%$ \\
\hline $1050-1099$ & $1,6 \%$ & $5,3 \%$ \\
\hline $1100-1149$ & $0,5 \%$ & $0,2 \%$ \\
\hline $1150-1199$ & - & $0,1 \%$ \\
\hline $1200-1250$ & $4,07 \%$ & $2,7 \%$ \\
\hline s. d. & - & $0,36 \%$ \\
\hline
\end{tabular}

2.3. Das cifras de emprego relativo que nos ofrecen estes dous cadros conclúese que tanto lagar como torcular acadan a porcentaxe máis elevada de utilización na primeira metade do XI aínda que torcular dobra os usos de lagar. Esta situación de preponderancia de torcular xa a advirte P. Rodríguez cando afirma que "Su uso se hace cada vez más frecuente, llegando a ser dominante y suplantando a lacar en la documentación latina medieval de los siglos XI y XII" (1983: 705).

Mais no século XIII sucede practicamente o contrario. Ante isto xorde unha pregunta $i$ a que se pode deber esta inversión de porcentaxes de utilización de dous termos que, en principio, son susceptibles de significar o mesmo e de seren utilizados nos mesmos contextos? Na nosa opinión, este fenómeno é explicable dende a análise dos contextos nos que un e outro se empregan. Despois do estudio destes vocábulos, distínguense con claridade tres ámbitos de uso: descricións enumerativas de tipo formular dos elementos dunha propiedade ${ }^{10}(\mathrm{~F} 1)$, fórmulas de pagamento dun canon en especie (F2) e logo os que denominamos

10 Estas enumeracións tipolóxicas son as coñecidas como "fórmulas de pertinencia", cf. O. Guyotjeannin, J. Pycke et B.-M. Tock (1993: 82). 
usos libres, por estaren afastados da contorna formular (L). A táboa seguinte sinala a distribución das ocorrencias das dúas palabras nos contextos mencionados:

\begin{tabular}{|l|c|c|c|}
\hline & $\mathrm{F} 1$ & $\mathrm{~F} 2$ & $\mathrm{~L}$ \\
\hline lagar & $11,2 \%$ & $66,3 \%$ & $22,4 \%$ \\
\hline torcular & $62,6 \%$ & $26,8 \%$ & $10,5 \%$ \\
\hline
\end{tabular}

Pois ben, torcular rexístrase maioritariamente entre os séculos X-XI debido á proliferación neste período de enumeracións tipolóxicas dos diversos elementos dunha propiedade ${ }^{11}$, para as que, pola súa propia natureza, sería máis axeitado o termo tradicional, ben coñecido ademais nos dominios ultrapirenaicos ${ }^{12}$. Pola contra, lagar documéntase, sobre todo anque, como veremos, non de xeito exclusivo, na primeira metade do XIII en fórmulas de pagamento de rendas forais. A escolla da forma viva do romance podería relacionarse coa procura da claridade comunicativa, do inequívoco co fin de que non se suscitasen dúbidas sobre os termos do pacto. Así e todo, é interesante comprobar que tamén torcular acadou un índice de uso importante neste tipo de contratos, explicable non só por ser o XIII un século de mellor coñecemento da latinidade que conlevaba a preferencia por formas tradicionais e o afastamento das romances senón posiblemente tamén porque gozaba dunha tradición formular, xurídica en último caso, que conviña moi ben á lingua dos contratos. Por outra banda, o escaso índice de participación de torcular fóra dos ámbitos estrictamente formulares, ocorre tamén na súa meirande parte no século XIII, o que parece demostrar que non era unha palabra viva no romance do noroeste peninsular ${ }^{13}$.

11 Un estudio profundo sobre este tipo de enumeracións pódese ler en M. Zimmermann (1989-1990).

12 Incluso é posible encontralo en certas enumeracións de bens anque quizais desprovistas do marcado carácter tipolóxico que teñen as nosas, por exemplo, no POLYPT. Rem. p. 1, a. 861, et mansus dominicatus, cum aedificiis et torculari, curte et scuriis et horto.

13 Sen embargo, nun documento bastante anterior, do 1075 do CARTUL. S. Emil. Cocul. rexístrase a forma troliare. 


\section{O ASPECTO GRÁFICO}

3.1. O aspecto gráfico de lagar require unha clasificación das diversas variantes ${ }^{14}$ en tres grupos ${ }^{15}$ :

a) Formas con - $g$ - / Formas con $-c$-. .

Tan són un 3\% do total das mencións que recollemos de lagar responden a unha escrita que tenta achegarse a unha ortografía máis latina, isto é, con - $c$ - intervocálico ${ }^{16}$; pensamos que esta descompensación tan importante tería moito que ver coa falta dunha tradición escrita da palabra.

b) A forma laguare. Só temos tres exemplos: *Os. 523, $1243^{17},{ }^{*}$ Os. $552,1245 *$ Os. 557,1245 . Trataríase dunha grafía inversa ${ }^{18}$ xa que a labiovelar perdeu comunmente o elemento labiovelar ante - $a$ (agás algún comportamento dialectal), pero ante - e e - $i$ mantívoo a nivel gráfico.

3.2. Centrándonos en torcular, é preciso salientar a diversidade formal. En verdade, rexistramos numerosas variantes mais escasamente representadas fronte á xeral torcular/-are.

- corculari: só aparece en *CO. 198, $1243^{19}$ explicable como unha confusión de sons producto quizais do descoñecemento do termo.

- torgular: documéntase en Ce. 180, 1010, acta onde hai cinco mencións máis grafadas co tradicional torcular. Poderíamolo explicar

14 Non consideramos a forma largare (Ce. 390, 961) posto que semella ser unha gralla.

15 Na documentación asturleonesa as variantes son practicamente as mesmas, se ben, engadir outras illadas como laquare (a. 1096) en Álvarez Maurín (1994: 298) ou lacatare (a. 884) en Rodríguez Fernández (1983: 707)

16 Sen embargo, nos documentos asturleoneses que achega P. Rodríguez (1983: 707708) hai varios exemplos: lacar (a. 870); lacatare (a. 884); lacare (a. 978); lacares (a. 1046) á beira de formas con - $g$ - como lagare (a. 974). Pola súa banda, Álvarez Maurín (1994: 298), cita un laquare nun doc. de Sahagún do a. 1096, do cal a grafía -quante vocal denota un uso gráfico propiamente hispánico.

17 Vid. M. Romaní Martínez (1989).

18 Esta é tamén a explicación que dá M. Pérez González (1985: 78). para o nome de $B e-$ renguaria.

19 Vid. E. Duro Peña (1996). 
como un desmarque do escriba da grafía tradicional cara a representación dunha posible pronuncia romance ou sen máis un ensaio de grafía de tipo analóxico pois non era descoñecida na documentación a representación da oclusiva velar xorda co grafema da correspondente sonora.

- Relacionado cunha posible lectura [g] poderíase interpretar a variante co dígrafo - $q u$-, tipicamente hispánica, que representaría o fonema /k/ no único pero moi interesante exemplo de Ce. 135, 1104 que di así: torquulares uel in torculares. Polo demais, o mesmo fonema tamén podería verse grafado simplemente con - $q$ - como sucede en dous orixinais do século XIII: torqulari (Os. 356, 1231) e torqular (CO. 221, 1248) ${ }^{20}$.

\section{MORFOLOXÍA}

4.1. A forma máis recorrida é lagare que supón un $56 \%$ das mencións, logo lagar (17\%) e lagari cun $14 \%$ aproximadamente cada unha delas. A abundancia de lagare débese a dúas razóns: a que o caso ablativo é o preciso na maior parte dos contextos e a que tanto lagar como lagare poden funcionar como formas neutras ou como unha especie de caso universal, véxase, uini in lagar $*($ Me. 43,1222$) \sim$ uinis in lagare $*($ Me. 33, $1219)$ ou ad lagar *(SC. 37, 1224) $)^{21} \sim$ ad lagare (Ce. 519, 998). Entre estas dúas formas parece albiscarse unha diferencia cronolóxica posto que as formas sen - $e$ final son máis tardías, encontrámolas exclusivamente na segunda metade do século XIII. Con respecto a lagari, ablativo singular dun neutro da terceira declinación, é típico da colección de documentos da catedral de Ourense; aparece só como termo de preposición e, tal vez, o seu uso tal vez estea relacionado coa procura dunha diferenciación con lagare e dáse asemade sobre todo na primeira metade do XIII, período no que se albisca unha melloría nos coñecemento do latín.

Na maior parte dos casos, a voz aquí tratada semella responder a un destes paradigmas: *lagaris,-is, *lagare, -is, ou á imaxe de torcular,

20 Tamén noutras actas noroccidentais, como esta dos Doc. cath. Ovet. p. 147, a. 1020, cum casas, oreos, cubbas, cum omnia torqularia, montes.

21 Vid. M. Lucas Álvarez e P. Lucas Domínguez (1996). 
* lagar, -aris. O xénero habitual no noso corpus é o masculino ${ }^{22}$, aínda que cabe a posibilidade do neutro, plural en ${ }^{*} \mathrm{CO} .117,1230$, et in sumitate ipsius uinee faciatis domos et ponatis in eis lagaria e tamén singular en Ce. 165, 963, super illud lagare fronte a, por exemplo, os seguintes masculinos, Ce. 202, 1009, damus uobis illum lagare; Ce. 163, 932, domus, terras, lagares ou *Me. 71, 1232, et ponatis lagarem...

4.2. En canto ó paradigma de torcular, ó ser unha forma tradicional a súa variabilidade é menor e responde basicamente ó clásico torcular,-aris, anque se aprecian tamén algunhas variantes. Por exemplo, ó igual que sucedía con lagare, a presencia do - e final en torculare é polisémica: indica, sobre todo, un ablativo -casare qui est concluso cum sua uinea et sua casa una et suo torculare (Ce. 324, 1045)-mais tamén, en contadas ocasións podería funcionar coma unha forma neutra ou coma caso réxime universal, véxase, Ce. 540, 1031, damus uobis ibidem casas et casares, uineas et torculare, figares... ou Ce. 184, 1003, super illo torculare.

Sen embargo, no terreo morfolóxico o factor de variación máis importante é o xenérico que enfronta un masculino torculares fronte a un neutro torcularia. Despois de facer un reconto dunha é doutra, só se aprecia unha lixeirísima preponderancia do neutro plural, un 5\% máis aproximadamente ${ }^{23}$. Con respecto ó xénero, cómpre destacar que tan só contamos con dous acusativos que responden claramente a un masculino singular, ou sexa, torcularem, en Ce. 257, 929 e *Os. 261, 1225. Este ancoramento na morfoloxía tradicional haberíao que poñer en relación cos contextos formulares nos que se emprega a miúdo.

22 Tamén en CARTUL. S. Jacob. Legion. p. 155, 970, casas, cubas, lectulis, lagares.

23 Pola contra, na documentación asturleonesa que manexamos a penas encontramos a variante masculina plural: torculares rexistrámolo nun doc. de Sahagún do a. 1042 e noutro do a. 1098, cf. Álvarez Maurín 1994: 298). Tampouco é moi frecuente no masculino singular, anque é posible como neste doc. do a. 908 que dá P. Rodríguez (1983: 712), pomarem cum sua clusa et torcularem. Polo demais encontramos unha variante descoñecida no noso corpus e formada co sufixo -arium, entre outros, en CARTUL. S. Jacob. Legion. p. 172, a. 987, cum cubas, torcularios...; e tamén en alén dos Pirineos, por exemplo, en CARTUL. Lesat. p. 157, c. 990, casalem cum ipsas casas et orreo et torculario ou CARTUL. S. Vinc. Mass. p. 513, a. 1034, ipso cellario cum suo edificio et cum ipso torculario et cum ipsas uineis. 
Por último, encontramos tamén moitas ocorrencias da forma torculari; a primeira atopámola en So. 484, 1181, habet iacentia sub meo torculari. Non obstante, o seu uso xeneralízase no século XIII e en concreto nas fórmulas de pago dos contratos forais. Así aparece rexido habitualemente pola preposición in: in torculari $*(\mathrm{CO} .99,1225)$, por exemplo; na expresión desta fórmula concorre coa variante in torculare (Os. 346, 1231), ou coa expresión ad torcular. Pois ben, este ablativo en $-i$ característico dos neutros da terceira declinación, cremos que hai que tomalo como producto dun coñecemento máis profundo do latín no século XIII á vez que permite unha distinción coa forma torculare que posuía maiores posibilidades sintácticas.

\section{O SIGNIFICADO}

Non resulta sinxelo determinar con precisión a natureza significativa destes termos nos nosos documentos debido a que a maioría das mención atópanse en contextos formulares, sobre todo, en fórmulas de pertinencia e nas de pagamento de certas rendas. Por iso, dispoñémonos a distinguir eses usos das mencións que aparecen fóra destes ámbitos, que nós denominamos coma usos libres. Por outra parte, tamén nos valeremos da pervivencia nas linguas romances onde, por exemplo, no galego tan só perviviu lagar coas acepcións de 'pía onde se pisa a uva para espreme-lo mosto'; 'lugar onde se prensa a mazá ou a oliva' e "edificio onde se prensan estes froitos" ${ }^{24}$; o castelán trujal que, entre os seus significados conta cos de "prensa donde se estrujan las uvas o se exprime la aceituna', 'molino de aceite' ${ }^{25}$. Con estes sentidos, pode aparecer nos documentos medievais como veremos de seguido nunha análise máis detallada.

24 Vid. M. C. Ares Vázquez et al. (1993: s. v.).

25 Vid. DRAE, s. v. 


\subsection{As ACEPCIÓNS E CONTEXTOS DE LAGAR}

Quizais o feito de ser un termo que perviviu no romance non atraeu demasiado a atención dos investigadores. Así Floriano Cumbreño (1951: 725) mencionábao tan só como unha parte ou departamento da casa se ir máis alá. P. Rodríguez (1983: 704), pola súa banda, sinala tamén que "el lacar o torcular, junto con el orreo y a veces la apoteca, constituyen las dependencias básicas en torno a la casa rural. En el lagar o torcular, y también en la bodega, se guardan las cupas que generalmente contienen sidra o vino. Aunque el lagar está íntimamente vinculado a la casa, incluso dentro de la misma: cum casa et suo lacare in ea (SV. 99, 1086) también hay lagares en medio de las pomaradas y las viñas”. Finalmente da análise de Álvarez Maurín (1994: 298) tan só podemos concluír que eran un tipo de edificacións. Daquela dispoñémonos a analizar a distintas ocorrencias de lagar no noso corpus atendendo ó seu uso contextual.

\subsubsection{Lagar en usos libres}

a) Edificio ou lugar onde está a prensa.

Este tipo de edificacións podían constituír unha dependencia básica dunha explotación agraria tipo corte ${ }^{26}: \mathrm{Cb} .28,1075^{27}$, do tibi unam curtum de Quintana cum quoquina et cellario, lagare, cubam unam plenam de uino, dunha uilla ou dunha hereditas, por exemplo, *Me. 48, 1224, et ponatis lagar in eadem hereditate supradicta in qua torquatis unas

En calquera caso, nas actas apréciase un notable vínculo cos elementos do sector habitacional como se enxerga da secuencialidade de termos, véxase, Ce. 390, 961, medietate de illas casas et de illo largare ou en *Os. 220, 1222, De casa de Riales et de lagari et de cortina habet Fernandus... ou nas propias enumeracións descrivas de carácter formular (v. infra).

26 Tamén en Doc. cath. Ovet. p. 149, a. 1033, corte con kasas, cubas et orreos, lagare, lectos, selas, omnia uasilia...

27 Vid. M. Lucas Álvarez (1957: 199-223. 1958a: 221-308 e 1958b: 547-639). 
Pero tamén hai lagares afastados dos lugares de habitación, en heredades, $*($ Me. 52,1225$)$, et ponatis lagar in eadem hereditate in quo exprimatis uuas... e, incluso en *(Me. 75, 1232), deinde faciatis unum lagare in ipsa uinea que tenuit Petrus... constrúese un no medio dunha viña. Pola súa banda, en Ce. 368, 1009 encontramos unha viña a carón dun lagar, et iacet ipsa uinea in loco predicto iuxta lagare.

Por outra parte, o seu relevo na paisaxe é aproveitado como elemento referencial para determinar os lindes de certas propiedades (cf. *Os. 212, 1221, concedo meam searam quam habeo in Francelus et iacet inter lagare Arie...). Por isto mesmo coidamos que motivou algúns topónimos ou microtopónimos como Lagares (So. 136, 1152) ${ }^{28}$ ou Lagar *(Os. 606, 1248).

A partir dos nosos diplomas parece doado establecer a dedicación principal deste tipo de construccións: lugar de elaboración do viño. Son numerosas as razóns que nos levan a esta conclusión:

- noticias como et ponatis lagar in eadem hereditate supradicta in qua torquatis uuas *(Me. 48,1224$)$ ou lagar in eadem hereditate in quo exprimatis uuas $*($ Me. 52,1225$)$.

- a súa asociación ó viñedo en diferentes contextos, por exemplo, En Ce. 373, 956 véndense as viñas e os lagares, uendideramus uineas, lagares et omnia.. e sobre todo nas fórmulas forais nas que se establece a cantidade de viño do lagar que habería que pagar, por exemplo, *Me. 43, 1222 ut plantes eam de uinea et labores eam et des inde nobis anuatim terciam partem uini in lagar, ou ben, quartam uini in lagare de ipsa uinea in tempore uindemie *(Os. 622, 1249).

Non obstante, tampouco cómpre descartar a súa utilización para obter sidra. Non temos ningún dato concreto que relacione directamente lagar e esta bebida, a non ser que consideremos a presencia en enumeracións de uineas e pumares ou só pumares como Ce. 519, 998, uilla in domos, lagares, terras cultas et incultas, pumares uel omnia... ou Ce. 204,1005 , in casas, in lagare, in uineas, pumares, terras... Sen embar-

28 Vid. P. Loscertales de García de Valdeavellano (1976). 
go, ó longo da nosa documentación existen numerosas referencias a esta bebida que tamén se obtiña nos lagares.

En canto ós enseres que habería no seu interior, isto é, os intrinsecis suis de Ce. 529, 953, tan só se explicitan en *CO. 220, 1248, et lagare de Auria cum sua tinnalia et quilibet debet habere; segundo Viterbo, $\mathrm{s}$. v. tinalha, eran uns recipientes a modo de pequenas cubas que "serve, principalmente, para recolher, conduzir, e pisar as uvas, e guardar ainda o mesmo vinho". Polo demais, temos bastante exemplos, sobre todo, en fórmulas de pertinencia da vinculación con lagares co par cupos-cupas que, nestes contextos, máis que ter por referente a obxectos individuais poderían representar un xenérico relativo a todos os recipientes necesarios para a elaboración do viño e/ou da sidra, Sa. 94, 1011, cum omnibus edificiis, casas, lagares, cupas, cupos et omnia uasa uel quantum ad prestitum hominis est.

b) Prensa propiamente dita.

Encontrámola dentro dunha bodega en Cv. 79, 1108 ${ }^{29}$, et est ipsa hereditate cum casa murina et regulata et alia casa que est bodega cum lagare et cum cubas et regulata. ou ben no interior dunha domus, et in sumitate ipsius uinee faciatis domos et ponatis in eis lagaria *(CO. $117,1230)$. Neste caso, é difícil saber se estaban dentro da vivenda ou se eran simplemente construccións anexas a ela anque semella máis o primeiro caso como tamén en CARTUL. S. Vinc. p. 173, a. 1086, nostra ratione de illo solare cum una casa et suo lacare in ea.

Este valor non é, dende logo, o fundamental no noso corpus. Pola contra, Pascual (1985: 709-720), depois dun estudio minucioso do lagar na Ávila medieval a través da documentación en castelán da súa catedral (ss. XIII-XIV) conclúe que o valor fundamental era o de "prensa ${ }^{30}$ e que só en ocasións "hacían referencia, igual que hoy en día

29 Vid. J. I. Fernández de Viana et al. (1996-1997).

30 Para este investigador, os lagares para a obtención de viño estaban ubicados en portais abertos, "construidos delante de las bodegas o casas, que, si bien solían estar techados y mantenían, por lo tanto, la viga cubierta, no faltaban casos en que, al no existir la protección de un tejado, quedaba descubierta la viga..." (1985: 710-711). 
y por una razonable sinécdoque, al edificio en que estaba la prensa". En cambio, os nosos documentos parecen apuntar cara á situación inversa ó se referir de xeito primordial á acepción de 'lugar ou edificio onde está a prensa'. Por outra parte, non é nada raro se pensamos que, orixinariamente, o sufixo - ar engadiría un valor locativo a lacus.

c) Explotación vitícola.

Xa vimos arriba que os lagares podían situarse afastados do núcleo poboacional, sobre todo, no medio dos viñedos. Pois ben, o lagar podería converterse ademais no punto central dunha explotación adicada a viticultura segundo se tira de Ce. 315,1031 , concedimus uobis in ipso lagare uno petazo de uinea qui iacet cum ipsa uinea... O mesmo semella doutras actas das coleccións documentais próximas como en CARTUL. S. Vinc. p. 91, 1046, oreos, cupas, lacares cum suis uineis.

\subsubsection{Lagar en enumeracións descritivas}

Como xa sinalamos arriba, non é este un uso frecuente pois representa pouco máis dun $11 \%$ das nosas mencións ${ }^{31}$, como por exemplo, Ce. 163, 932, ipsam quintam in domus, terras, lagares, uineas, pumares, cersares, nogares, ficares... A escasa presencia neste tipo de contextos poderíase explicar por ser unha voz propiamente hispánica, ausente nas principais coleccións formulares ou textos legais medievais, daquela, carente de tradición xurídica ou formular fronte ó sinónimo torcular.

En canto á súa disposición na estructura orgánica destas enumeracións, ás veces lagar sitúse entre os elementos propios do sector de habitación e hortas, pensamos que debido a que era considerado como un edificio, unha dependencia máis da explotación agrícola ${ }^{32}$ para a obten-

31 Tampouco é frecuente nos ámbitos próximos anque non é descoñecido este uso, véxase, CARTUL. S. Jacob. Legion. p. 228, 1017, de medietate de uilla nostra propria uocitata Antimio: cortes, kasas, lagare, cubas, lectos, perfia ou p. 155, a. 970, in ipsa uilla, cum cortes, casas, cubas, lectulis, lagares...

32 Non é raro que tanto lagar como torcular aparezan en singular neste tipo de enumeracións altamente formalizadas, indicando o seu carácter único para toda a explotación; pola mesma Ce. 177, 952, á hora de realizar a enumeración descritiva dunha villa, 
ción do viño e, nalgún caso, da sidra, por exemplo, So. 55, 995, in casas, in lagare, in pumares, in cerdares, in castaniares..., Ce. 519, 998, uilla in domos, lagares, terras cultas et barbaras... e Sa. 94, 1011, uilla..cum omnibus edificiis, casas, lagares, cupas, cupos et omnia uasa uel quantum ad prestitum hominis est... ou Ce. 197, 1011, uendimus uobis in homnibus domos omnem utensilia, lagare, terras, uineas, pomeriis, arbores fructuosas uel infructuosas, montes, aquis, petris, accessu uel recessu, cum omnibus eductibus suis et..., entre outros.

Por outra parte, en certas mencións esta voz aparece desprazada do espacio habitacional, remitindo quizais a esa posibilidade de que os lagares se construísen preto das explotacións agrícolas; tal poderían transmitir casos como Ce. 163, 962, in domus, terras, lagares, uineas, pumares, cersares... ou Ce. 222, 954, damus uobis domus, uillas, terras, pumares, pascuis, padulis, molinus, lagare quantum ad prestandum est.

Por último, incluso cabería a posibilidade de conxecturar que nalgunha enumeración aludise á prensa propiamente dita; sería en mencións onde aparece á beira doutros enseres propios domésticos como Sa. 91, 967, dono et testo ecclesie uestre domos quas ibi edificaui, lagarem, cupos, cupas, tulias ${ }^{33}$, lectos, cathedras, mensas... ou noutros cartularios, en CARTUL. S. Vinc. Ovet. p. 33, 974, casas, orreos, aboteciis, cupas, lagare, lectos, sellas, mensas... Alomenos, para o noso exemplo, parécenos pouco probable e na nosa opinión segue a se referir á idea de lagar como edificio que desenvolve na enumeración, de xeito secuencial e progresivo, algúns dos seus posibles enseres.

\subsubsection{Lagar en fórmulas de pagamento}

Esta é a función contextual maioritaria do noso termo como reflicte o cadro estatístico proposto arriba. Con todo, para este termo en particular, hai que diferenciar dúas posibilidades:

malia o seu elevado ton formal, destaca a presencia de dous lagares, Sic eam uobis ab omni integritate concedo quomodo illam ab integro tenui in meo iure, casas, uineas, terras, saltus, exitus atque regresus, lagares duos, intrinsecus domorum, cupos, cupas,...

33 É incorrecta a lectura talias que dá o editor. 


\section{a) en fórmulas exclusivas do mosteiro de Celanova (992-1051).}

En total, repertoriamos unha ducia de actas deste mosteiro nas que lagar aparece indefectible unido a area, en distintos tipos de actas, para indicar certo tipo de pagamentos ou canons baixo a expresión ad area et ad lagare ou a inversa. Por ser un feito e unha expresión singular no noso corpus e atreveríamonos a dicir, en xeral, na documentación, ímonos deter un pouco no seu estudio.

Encontramos este uso en varias cartas de incomuniación como Ce. 490, 992, onde a propiedade entregada ó mosteiro polos doadores será traballada a cambio do pagamento dun canon anual de viño e cereais, a saber, kartula incommuniationis...facimus de omnem nostram hereditatem medietate integra... ut in uita mea per singulis annis do uobis ad area et ad lagare de uino medietate et de pane quarta... Et illa medietate teneamus illa nos et filiis nostris uel neptis... et demus uobis ad area et ad lagare quod desursum resonat...; outras veces establecíase unha carta de incomuniación sobre unha propiedade para obter protección ou defensa, como Ce. 519, 998, damus uobis de ipsa uilla...quinta integra...uobis damus atque concedimus, ut habeamus de uos moderationem et defensionem, et demus ad area et ad lagare quinta integra de quantum nobis Dominus dederit; ou como satisfacción dun adulterio, como sucede en Ce. 547, 1022, incommuniationis de hereditate.... Et demus uobis per annis singulis ad area et ad lagare medietate tam de pane quam de bibere quam etiam et de omnes fruges quod Dominus in ipsa uilla dedit, medium uobis demus et medium remaneat pro nobis.

E ademais atopamos a utilización da expresión ad area et ad lagare vencellada os chamados na documentación noroccidental "renovos" ${ }^{34}$, ou sexa, préstamos a rédito, case sempre de áridos e líquidos, que concedían os grandes propietarios ós pequenos en épocas de malas colleitas. Ante unha eventual imposibilidade de devolver o préstamo, agravado cos intereses correspondentes, o deudor cedía ó acreedor a

34 O estudio deste tipo de préstamos a rédito de bens en especie do que nos servimos é o de L. G. de Valdeavellano (1973) . 
totalidade ou parte das súas terras. Esta práctica usuraria ${ }^{35}$, malia estar condenada pola Igrexa, encontrámola ben documentada nos actas asturleonesas dos séculos X-XI e, sobre todo, na documentación de Celanova con matices diferentes en canto á forma de pagamento. En Ce. 473, 1013, os dous deudores deste doc. entregan a súa heredade como pagamento dun renovo coa condición de que eles e a súa descendencia puidesen seguir vivindo e traballando nesa propiedade tras establecer unha especie de acordo de aparcería segundo o cal entregarían ó acreedor, o novo propietario, a metade dos froitos ad area et ad lagare. Velaquí a pasaxe correspondente á doazón de Deiservo, et damus ipsa uilla sic pro uestro renouo que non habemus unde uobis illo complere, id est pane et bibere modios CCCC XX et III quartarios et sestario I. Et facimus uobis ipsa kartula ut in uestra uita tamdium uixerimus, sedeamus in ipsa uilla et laboremus, fundemus et adpligemus, et demus uobis ad area et ad lagar medium de omnem fructum quod Dominus in ipsa uilla dederit. Et post obitum uero nostrum sedeant filiis nostris et neptis in ipsa uilla, et laborent et parciant uobiscum per medio.... Dun xeito semellante parece poder interpretarse Ce. 484, 1013, damus uobis ipsa uilla pro uestro renouo que non habemus unde illo complere... et facimus ipsa kartula ut demus uobis ad area et ad lagare medietatem integram de omnem fructum.

Noutras ocasións, estamos ante unha especie de venda ${ }^{36}$ como é o caso de Ce. 465, 1032, uendimus ipsa hereditate....ubi medietate de ip-

35 Según L. G. de Valdeavellano, trátase "en casi todos los casos de la usura que la Lex Visig. 5, 5, 9, Antiqua denominaba "De usuris frugum" y que, según dicha ley, implicaba un interés del 50 por 100" (1973: 417). Velaquí o texto da devandita lei: De usuris frugum. Quicumque fruges aridas et humidas, id est, uinum et oleum, uel quodcumque annone genus alteri commodauerit, non plus ab eo propter usuram quan tertiam partem accipiat; id est, super duos modios qui accepit tertium reddat.

36 E aínda habería máis posibilidades documentais como Ce. 349, 1044, onde o presbítero Astrario doa varias propiedades a Celanova para ser admitido pero, seruata tamen rationem dum uitam ego aduixero ut habeam partem in eas sub cum pro stipendium meum in uita mea illas IIIes tercias et post parte uestre et sancti Saluatoris monasterii Cellenoue IIII integra ad area et ad lagare...; ou Ce. 572, 1012, onde pola axuda prestada polo mosteiro nun xuízo dóanse dúas uilas en parcería, ipsas ui- 
sa nostra hereditate ubi illa potueritis inuenire...et laboremus illa cum nostros boues et parciamus per medio uobis ad area et ad lagare... accepimus de uos precio uaccas II cum suos filios, ciuaria inter triigo et centeno modios X, uenape I $I^{a}$, boue uno, pelle una... ou Ce. 253, 1041, medietatem uobis inde concedimus ad perabendum de quanto solitum est discurrere ad aream et ad lagare... de uos pretium legitimum et idoneum caballum nimis obtimum colore amarello.

En calquera caso, a expresión ad area et ad lagare semella un fórmula xurídica que, a través da mención dos lugares onde se prepara e obtén a producción agrícola de áridos (pane) e líquidos (uino, bibere), estipula que se entregue unha determinada parte desa producción. Daquela, por veces, esta expresión podería aludir simplemente á producción de áridos e líquidos tras un cambio semántico xanerado por un proceso metonímico de continente por contido.

b) Por outra banda, a finais do século XII inícianse en Galicia un tipo de concesión de terras a familias campesiñas polas que se esixe unha renda: son os foros. Cando o importe solicitado consiste en viño -a lagaradiga ${ }^{37}$, segundo Viterbo, s. v. areatica- e cereais, o realmente rechamante é que se continúa a formulación xurídica dos documentos que acabamos de ver empregando lagar para aludir á cantidade a entregar de uinum ou de bibere. E como xa dixemos arriba, é este o uso primordial de lagar no noso corpus ó representar preto do $67 \%$ das mencións; delas a máis antiga sería *Me. 8, 1203, medietate uini in lagare. Esta preferencia pode obedecer non só a que lagar era a forma romance e a súa utilización disipaba calquera problema de comprensión se-

llas... sic omnia uobis concedimus et inreuocabiliter ad perhabendum et perpetuum ad possidendum ut demus uobis pannis singulis (quizais por annis singulis) ad area et ad lagare tercia integra, tam de pane quam de bibere quam de omnes [felegreses]... et parciamos uobiscum.

37 A finais da primeira metade do século XIII temos as primeiras alusións directas a este termo no noso corpus: ${ }^{*}$ Me. 101, 1242, det nobis I solidum de lagaradiga annuatim ou *Me. 109, 1244, Et quisquis tenuerit partem de hac uinea det nobis unum solidum de lagaradiga hanuatim. E con anterioridade en Doc. reg. Port. I, p. 32, a. 1111, In lagaradiga de uino de quinque quinales inferius dent almude et si fuerit dent quartam sine ulla offrecione et iantar. 
nón tamén a que xa fora utilizada en contextos e funcións semellantes, alomenos en Celanova, como acabamos de ver.

E do mesmo xeito encontramos certas formulacións nos foros que parecen recordar directamente aquelas que aparecían sobre todo nos renovos; non obstante a gran maioría de fórmulas que se utilizan para indicar a renda de bens en especie a pagar polo aforamento dunha determinada propiedade presenta unha maior riqueza terminolóxica; en función desto, distinguiremos dous tipos de formulacións:

b.1) Fórmulas simples

Baixo este epígrafe incluímos aquelas mencións nas que só se esixe a renda en especies, en áridos e líquidos, baixo a denominación metonímica dos lugares onde se preparan: a area e o lagar. A orde e o réxime preposicional destas dúas voces tamén vai propiciar a existencia de diversas variantes. Velaquí algún exemplos: *SC. 37, 1224, detis nobis medietatem ad aream et ad lagar et sub arboribus excepto quod diuidatis nobis : ; *Os. 228, 1223, layra... ut tu in duabus partibus plantes uineam et in una parte labores panem et predicta layram plantes usque ad fructibus habitis in ipsa hereditate in area et in lagaredes inde nobis; *Ra. $15,1230^{38}$, et detis de illa quartam partem fructus in area et in lacare et de fructibus arborum similiter; ${ }^{*}$ Os. 231, 1223, tali pacto damus eam uobis ut cultificetis et laboretis eam et detis inde nobis medietatem in lagare et in area ou CO. 59, 1217, det mihi meas directuras in pace al lagar et in area.

b2) Fórmulas complexas

Son as máis abundantes e denominámolas así porque se especifican os productos da colleita á beira dos lugares de preparación ou obtención amais de se estender de modo máis xeneralizado a demanda a outros froitos alén dos cereais e do viño ${ }^{39}$. A súas posibilidades variacionais establécense basicamente en función da orde dos elementos, do

38 M. Lucas Álvarez e P. Lucas Domínguez (1988).

39 Subliñamos a base común ás distintas expresións. 
propio número destes e das preposicións ou conectores sintácticos que os una. Velaí unha mada de exemplos:

*Me. 78,1233 , annuatim terciam panis et uini et omni fructu quod ibi euenerit post olera et porros, panem in haeram et uinum in lagare; *CO. 130, 1231, annuatim in perpetuum de omni grano, de uino, de serico et cepis tertiam partem, panem in area et uino in lagari; $* \mathrm{CO}$. 235,1249 , panem in area et uinum in lagare uel in uuis in uinea; $* \mathrm{CO}$. 148,1233 , et detis ipsi rectori tam de.pane in area quam de uino in lagare siue de uuis in uinea...; *Me. 33, 1219, terciam partem panis et uinis in lagare et in area; *Me. 93, 1239, annuatim terciam panis et uini et legumine in lagare et in area et pro fructa et pro cortina et pro castaneis panem in aurea uino uero in lagari; ${ }^{*}$ Os. 439,1238 , medietatem uini ad lagare... panis in area et medietatem castanearum ad cisternam detis monasterio; $*$ Me. 16,1210, medietatem uini adnuatim in lagare; $*$ Os. 501, 1242, medietate de uino in lagare et de castaneis in cisterna; *Me. 44, 1222, annuatim terciam uini in lagar et terciam de tritico et de centeno et de ordeo in area et quartam de milio et de panizo et de legumina et pro fructu arborum; *Os. 239, 1223, ut laboretis et eradicetis deinde montem... annuatim medietatem uini in lagare et medietatem de centeno et de tritico in area; et de ueraizo...; *CO. 121, 1230, quartam partem de uino in lagari et duos capones in Natali; *Os. 198, 1220, medietatem uini in lagar et medietatem panis in eirea et medietatem de totum granum et de totum aliud fructum; *Me. 41 , 1222, annuatim medium uini in lagar... panis in area, de castaneis...et pessigariis e, por último, ${ }^{*} \mathrm{CO} .117,1230$, annuatim in lagre de uino uel de uuis in uinea.

\subsection{AS ACEPCIÓNS E CONTEXTOS DE TORCULAR}

Orixinariamente significa a prensa e tamén o edificio no que se encontraba. Floriano Cumbreño (1949: 631), ó analizar o léxico dos diplomas astures confírelle o valor de 'prensas para o aceite' que non podemos admitir por ser excesivamente restrictivo. Pola súa banda, $\mathrm{P}$. Rodríguez, xa o vimos arriba, identificábao con lagar e, por último, Álvarez Maurín (1994: 298-299) parece concederlle os valores de edificio e mais o de prensa tanto de muíño como de lagar. 
Na busca da análise exhaustiva do seu significado, cremos que é útil o seu estudio partindo dos diferentes contextos de utilización, como fixemos con lagar.

\subsubsection{Torcular en usos libres}

Baixo esta denominación, queremos recoller simplemente aqueles usos que se afastan con claridade do ámbito formular. Xa demos conta da súa escaseza e tamén da súa limitación temporal, reducida en gran parte ó século XIII. Nestes casos, torcular ten fundamentalmente unha única acepción: edificio onde está a prensa. Serían construccións independentes ou como moito adxacentes a outras, segundo se enxerga a través dos seguintes indicios:

- a súa utilización como elemento demarcativo: Ce. 184, 1003, uinea que iacet super illa mea domo et super illo torculare ou *Os. 509, 1242, medietatem bacellarii... sicut diuiditur per torcular Lupi, exemplo do que se desprende un posible afastamento da poboación.

- as referencias á súa construcción ${ }^{40}: * C O .101,1226$, et faciatis ibi domos et torcular... ou *Os. 637, 1250, et faciamus in ipsa uinea infra annos premissos torcular in quo debemus et tenemus persoluere et dare abbacie totam medietatem uini

- a súa integración en unidades de hábitat-explotación máis amplas e a presencia, incluso, de viñas ou outras pequenas explotacións agrícolas no seu contorno co cal podería implicar certo afastamento dos núcleos poboacionais ${ }^{41}$ : Ce. 324,1045 , facimus de illo nostro casare qui est concluso cum sua uinea et sua casa una et suo torculare cum suo ortale...; *Me, 127, 1249 uinnas meas quas habeo cum suo torculari ou

40 Tamén noutros ámbitos, véxase, CARTUL. dom. Nigell. p. 132-133, a. 1172, nemo aliud ibi torcular possit edificare.

41 Outros documentos do cadrante noroccidental contribúen a observalo coma un tipo de dependencia ou anexo da casa rural pois aparece entre elas, é de ver, Doc. cath. Ovet. p. 169, a. 1046, orreos, torcularis, abotecis, cubas ou CARTUL. S. Vinc. Ovet. p. 93, 1046, ipsa uilla cum kasas, orreis, cupas, torcularia. Por outra parte, temos datos que o sitúan no interior dalgunhas fincas, nomeadamente, pomares e viñas, por exemplo, Doc. cath. Ovet. p. 78, 908, pomarem cum sua clusa et torcularem in ipso pomare. 
*Os. 615,1249 , et faciamus in ipsa uinea infra annos premissos torcular in quo debemus et tenemur persoluere et dare per maiordomum abbacie totam medietatem uini ipsius uinee...

Tal vez, nun número moi reducido de casos se refira á propia prensa, como no documento seguinte, onde se aludiría tamén ó seu aparallemento ou ós seus elementos: CO. 92, 1224, In domibus de Fontania duo torcularia cum omni apparatu suo... In Parada unum torcular cum omni apparatu et unam tinaliam et stramentum unius torcularis... In Urrous quodam magnum lignum ad opus torcularis... Tabula una ad opus torcularis. Un exemplo máis dubidoso é *CO. 107, 1227, et Iohannes Garsie habeat de doliis meis ad fructos colligendos tria maiora dolia et tinaliam unam cum torculari meo.

\subsubsection{Torcular en descricións enumerativas}

Como vimos arriba, este é o uso fundamental e case exclusivo do termo, e non só na documentación galega ${ }^{42}$, ó representar preto dun $63 \%$ do total das ocorrencias; de entre elas, a máis antiga, Sa. 99, ¿854?, construximus ecclesiam ipsam in amorem Dei omipotentis et casas, cellarium et quoquinam seu et torcular et pumares; et item ornatus ecclesie,...

De analizarmos a disposición de todas as ocorrencias no interior da enumeración, derívase como factor común a ubicación de torcular no espacio formular adicado ó nucleo habitacional dunha uilla ou hereditas xeralmente, cunha clara tendencia a situarse no segundo ou terceiro posto despois de casa ou domus ${ }^{43}$, por exemplo, Ce. 257, 929, heredita-

42 En documentos de ámbitos próximos: cf. LiB. fid. Brac., a. 1027, casas et uineas, labores, cortinas, torcular, fructeiras et aquas cursidas... ou nun diploma do 1020 dos Doc. cath. Ovet., cum omnia torqularia, montes, fontes, felcarias..., entre outros.

43 Na documentación asturleonesa, segundo puidemos analizar nos exemplos que dá P. Rodríguez, (1983: 712), a situación é semellante por canto se encontra no sector habitacional pero aparece vencellado casi indefectiblemente a orreos, termo moi raro no noso corpus, e/ou ó par cupos-cupas. Daquela, o modelo enumerativo non semella ser exactamente o mesmo. Velaquí algúns destes exemplos: a. 857, orreis, cubis, torcularibus; a. 1020, cum casas, oreos, cubbas, cum omnia torqularia; a. 1073, cum casas, orreos, cubas, torcularia. 
tem quicquid iusum sumus habere, in domos, torcularem, utensilia, terris, uineis, pomeriis, saltos uel omnia ligna fructifera et arboribus, ad stipendium abtis, accessu uel recessu montis, pascuis, paludibus,... ou Ce. 204, 1005, damus ibidem casas, torcular, casales, pumares, cersales, perales, sautos, deuesas, uineas, terras cultas uel incultas... A este respecto, non podemos apreciar ningún tipo de vencellamento de torcular cun destes dous termos, repartíndose case proporcionalmente a súa presencia a carón dunha ou doutra indistintamente ou incluso das dúas como en Ce. 305, 1022, hereditate domos, casas et torculare, terras, uineas,... Esto non impide que, a miúdo, apareza citado nas enumeración entre a vivenda e as viñas e dos pomares, ou sexa, representando un dos elementos dos que se serve o campesiño para transformar os productos agrícolas, por exemplo, en Ce. 375, 997, tam domos, torcularia, uineas, pumares, terras arruptas uel inruptas, arbores fructuosas uel infructuosas, aquis aquarum, exitus montium...; Ce. 180, 1010, uilla...in domos, torcular, uineis, pomeriis, saltos, deuesas et omnium frondium arbusculis ou mesmo Sa. 191, 1023, uilla...casas, torcularia et omnes arbores, terras, uineas, prata, pascua...

De estar deslocado cara as últimas posicións, agrúpase igualmente con elementos habitacionais, por exemplo, Ce. 516, 1039, damus uobis in ipsa uilla uineas, pumares, sautos, figares, amexinares, nogares, perales, deuesas, terras...petras mobiles uel inmobiles, casas, torcular, exitu et regressu... ou Sa. 146, 1076, uilla... cum cunctis prestationibus suis, montes, fontes, prata, pascua, sesigas molinarias, interius et exterius, domos cum edifitiis suis siue torcularia.

Algunhas excepcións como Ce. 193, 1007, in domos, in uineas, in pomares, in terras, in sautos, in torculare, in exitum... poderían suscitar a idea de construccións fóra no núcleo de poboación a semellanza do que sucedía con lagar e co que realmente podía suceder segundo indicaban os usos libres.

A acepción de 'prensa' tamén podería estar representada nalgunha enumeración descritiva como Ce. 9, 1045, Damus uobis in domos, casas cum suo torculare, terras, uineas, pumares, cesares... onde con casas parece referirse ó edificio onde se garda o torculare ou Ce. 343, 
995, in casas, cupas, cupos, zerereas, lectos, kathedras, mensas, torcular, uineas, terras, arbores, castaniares, mazanares... onde se sitúa á beira doutros enseres domésticos ${ }^{44}$. Con todo, non é estraño que nas enumeracións un elemento máis xenérico inicie a descrición dos seus compoñentes ou actúe como recopilador; tal é o que sucede en Sa. 239, 985, uilla meam rationem integram, casas, terras, arbores, prata, pascua, montes, fontes, cupos, cupas, torcularia, boues, uaccas et peccora promiscua; Sa. 97, 1074, uillas cum omnibus edifitiis suis intrinsecus uel de foris, casas, torculares, cupas, cupos, extrinsecus terras... ou Sa. 200, 1075, casas, sobrado et palatia, cupos, cupas et torcularia... Na nosa opinión, nestes casos, segue a referirse ó edificio onde está a prensa.

Finalmente, cómpre destacar o feito de que lagar e torcular son incompatibles ${ }^{45}$ na mesma secuencia formular agora ben, non no mesmo documento, como acontece en Ce. 204, 1005, que ademais revela unha estructura orgánica das enumeracións que conteñen un e outro termo semellante, a saber, medietatem siue in casas, in lagare, in uineas, pumares, terras fronte a casas, torculare, uineas, pumares, terras arruptas uel inruptas...

\subsubsection{Torcular nas fórmulas de pagamento}

Este uso tan só o documentamos nun determinado tipo de contratos, nos foros, durante o século XIII. Cando o que se esixía en renda era viño, normalmente empregábase a fórmula uinum in lagare ou unha va-

44 No corpus asturleonés esta é unha posibilidade moi común pois, en efecto, é moi frecuente que os torqulares se sitúen entre a enumeración de utensilios relacionados coa elaboración do ciño ou da sidra, por exemplo, a. 1084, casas, orrea, abotegas, cupas, torcularia ou a. 1197, orreis, cupis, torcularibus (P. Rodríguez 1983: 712) ou nun doc. de Eslonza, a. 1081, cupas, torcularias, mesas, sedilias (Álvarez Maurín 1993: 298).

45 Só encontramos unha excepción nun doc. de Sahagún a. 1098, cum casas, torculares, cupas, lacares (Álvarez Maurín 1994: 298). Neste caso se atendemos a orde secuencial torculares serían os edificios e lagares a prensa. Agora ben, non debemos esquecer que se trata dunha enumeración de ton formular onde primar o significado global sobre o individual de cada un dos compoñentes. 
riante formal. Sen embargo, ás veces, o termo lagare é substituído por torculare que non só gozaba de tradición xurídica ${ }^{46}$ senón que ademais representaba a forma latina tradicional que, nesta época, sería de gusto e preferencia dos notarios para amosar a súa melloría dos coñecementos do latín fronte á coincidente coa romance ${ }^{47}$. Non obstante, coidamos que, entre outros factores, a propia necesidade dunha clara comprensión motivou o triunfo neste tipo de fórmulas do sinónimo lagar.

Daquela, para a súa análise sería pertinente partir da mesma diferenciación que estableciamos para lagar mais non atopamos as que chamabamos fórmulas simples. Por conseguinte, só nos quedan as complexas que se producirán de xeito análogo ás constituídas por lagar:

*CO. 46, 1209, de uino uero terciam uini ad torcular, et non intres ad colligendos fructus sine ministro meo; *Me. 90, 1237, quartam partem uini per nos in torculari; $*$ Me. 88,1236 , terciam partem uini in torculare; *Me. 32, 1218, quod ad torcular uini dimidium tribuatur; *CO. 222, 1248, mando...VI modios ad torcular de uino; *Os. 531, 1244, III $^{\text {am }}$ partem omnium fructuum annuatim in torculari; $*$ Me. 86 , 1235 , medietatem de uino in torculare et quartam de castaneis in cisterna si ibi feceretis illas; et si uinea deffecerit, detis terciam de pane in area; *Ra. 26, 1238, quarta parte tocius fructus annuatim, uinum in torculari et alis fructus quas ibi habet, ad pedes de ipsas arbores quod ibi habebat et ducas ad cellarium; *CO. 99, 1225, terciam de pane et de uino, pane in area et uinum in torculari; Os. 346, 1231, de pane in area et III de uino in torculare; ${ }^{*}$ Ra. 27,1239 , quod tenuerit ipsum ca-

46 E non só polo seu emprego nas fórmulas de pertinencia senón en fórmulas semellantes en ámbitos bastante afastados coma o catalán, por exemplo, no CARTUL. Popul. p. 146 , a. 1196, donec fratres predicti monasterii in area uel torculari de predictis $C$ solidos sint bene paccati.

47 Noutra ocasión xa vimos como a partir da segunda metade do s. XII comezan a manifestarse na redacción notarial, con igual ou maior intensidade, aqueles termos dunha parella de sinónimos que non perviviron no romance e que ata o de entón eran practicamente descoñecidos ou cando menos inusuais na práctica notarial; poñiamos, por exemplo, a preferencia de equus fronte a caballus ou a de aries fronte a carnarius, cf. Xaime Varela Sieiro (no prelo). 
sale, panis in area et uinum in torculari; ${ }^{*} \mathrm{CO} .191,1242$, panem in area et uinum in torculari; $*$ Me. 117,1245 , pane in area et uino in torculari; *Ra. 19, 1233, concedimus ipsum montem per suas diuisiones tali pacto quod dirumpatis et laboretis eum et detis... quarta parte fructus, panis in area et uinum in torculari uel uuas in uineam; *Ra. 25, 1238 , panis in aeira et uinum in torculari et castaneas in cisterna et ducatis ad cellarium sancti Petri; *Ra. 33, 1244, persoluatis panis in area et uinum in torculari et de alias fructas ad pedes arborum ou *Os. 335,1231 , unam talegam de centeno in area uel unum sextarium uini in torculari.

\section{CONCLUSIÓNS}

Ó longo desta exposición tentamos seguir os trazos de dúas voces, torcular e lagar, na documentación medieval de Galicia (s. VIIIa.1250) con achegas de datos das actas dos dominios próximos. A primeira era a forma tradicional, clásica, para identificar unha prensa ou o edificio onde está a mesma; a segunda é un hispanismo que comeza a manifestarse na documentación noroccidental. Entre unha e outra voz non apreciamos diferencias semánticas importantes no noso hábeas -tampouco cuantitativas- e aluden fundamentalmente ó edificio onde está a prensa para a obtención do viño e, quizais tamén da sidra; ambas as dúas tamén son susceptibles de seren utilizadas no mesmo tipo de contextos. A diferencia fundamental entre esta parella de sinónimos é a cronolóxica motivada por un certo tipo de especialización contextual: lagar úsase, sobre todo, na segunda metade do s. XIII en fórmulas de pagamento de rendas forais e torcular, pola contra, durante o século $\mathrm{X}$ $\mathrm{XI}$ nas moi recorridas enumeración tipolóxicas, denominadas fórmulas de pertinencia. 


\section{BIBLIOGRAFÍA}

Álvarez MAURín, M. P. (1994): Diplomática asturleonesa: terminología toponímica, León, Universidad de León.

Ares VÁzQuez, M. C. et al. (1993): Diccionario Xerais da Lingua, Vigo, Xerais, $4^{\mathrm{a}}$ ed.

Cb. LuCAS Álvarez, M. (1957): "La colección diplomática del monasterio de San Lorenzo de Carboeiro", Compostellanum, II/4, pp. 199-223.

(1958a): "La colección diplomática del monasterio de San Lorenzo de Carboeiro", Compostellanum, III, 2, pp. 221-308.

_- (1958b): "La colección diplomática del monasterio de San Lorenzo de Carboeiro", Compostellanum, III/4, pp. 547-638.

Ce. Andrade Cernadas, J. M. (1995): O Tombo de Celanova: estudio introductorio, edición e índices (ss. IX-XII), Santiago de Compostela, Consello da Cultura Galega.

CO. Duro PeÑA, E. (1996): Documentos da catedral de Ourense, Santiago de Compostela, Consello da Cultura Galega.

Cv. Fernández de Viana, J. I., J. C. de Pablos Ramírez e M. T. GonzÁlez BALASCH (1996-1997): "El Tumbo de Caaveiro". Cátedra. Revista eumesa de estudios, 3, pp. 267-437 e 4, pp. 221-385.

DRAE (1984): Diccionario de la Real Academia Española, Madrid, Espasa-Calpe.

ERnout, A. e A. MeILlet (1985[1932]): Dictionnaire étymologique de la langue latine. Histoire des mots, Paris, Klincksieck, $4^{\mathrm{a}}$ ed.

Floriano Cumbreño, A. C. (1949-1951): Diplomática española del periodo astur. Estudio de las fuentes documentales del Reino de Asturias, Oviedo, Imprenta La Cruz.

ForCELlinI, E. (1858-1875): Totius latinitatis lexicon, Prato, Aldina.

Guyotjeannin, O., J. Pycke e B. M. Tock (1993): Diplomatique médiévale, Turnhout, Brepols.

Loscertales de García de VAldeavellano, P. (1973): "El "Renovo". Notas y documentos sobre los préstamos usurarios en el reino asturleonés (siglos X-XI)", Cuadernos de Historia de España, 57-58, pp. 408-448.

Machado, J. P. (1990): Dicionário Etimológico da Língua Portuguesa, com a mais antiga documentação escrita e conhecida de muitos dos vocábulos estudados, Lisboa, Livros Horizonte, $6^{\mathrm{a}}$ ed.

Me. Soto LAmAS, M. T. (1992): La colección diplomática del monasterio cisterciense de Melón, Ourense (Pergaminos de la catedral de 
Ourense), ss. XII-XIII, Tese de licenciatura inédita, Universidade de Santiago de Compostela.

Os. Romaní MarTínez, M. (1989): A colección diplomática do mosteiro cisterciense de Santa María de Oseira (Ourense), 1025-1310, Santiago de Compostela, Tórculo.

PASCUAL, J. A. (1985): "El léxico relacionado con el lagar en castellano medieval", en J. L. Melena, ed., Symbolae Ludovivo Mitxelena Septuagenario Oblatae, Vitoria, Universidad del País Vasco, pp. 709720.

Pérez GonZÁleZ, M. (1985): El latín de la cancillería castellana (11581214), Salamanca-León, Universidad de Salamanca-Universidad de León.

Ra. LuCAS Álvarez, M. e P. Lucas Domínguez (1988): San Pedro de Ramirás. Un monasterio femenino en la Edad Media, Santiago de Compostela, Caixa Galicia.

Rodríguez FernándeZ, P. (1983): "El léxico de la sidra y el vino en la diplomática medieval asturiana en latín (siglos VIII-XIII)", BIDEA, 109-110, pp. 681-714.

Sa. LuCAS Álvarez, M. (1986): El Tumbo de San Julián de Samos (siglos VIII-XII), Santiago de Compostela, Caixa Galicia.

SC. LuCAS ÁlVAREZ, M. e P. LuCAs Domínguez (1996): El monasterio de S. Clodio do Ribeiro en la Edad Media. Estudio y documentos, Sada, Publicacións do Seminario de Estudos Galegos, Edicións do Castro.

So. Loscertales de García de VAldeavellano, P. (1976): Tumbos del monasterio de Sobrado de los Monjes, Madrid, Dirección General del Patrimonio Artístico y Cultural-Archivo Histórico Nacional.

ThLL. Thesaurus Linguae Latinae (1983- ), Leipzig-Stuttgart, Teubner.

VAREla SieIro, X. (no prelo): "Sobre a sinonimia na documentación altomedieval de Galicia", en Actas del III Congreso de la Sociedad de Estudios Latinos (Lugo-Santiago, septiembre 2000).

Viterbo, J. de Santa Rosa (1983-1984 [1798-1799]): Elucidário das palavras, termos e frases quen em Portugal antigamente se usaram..., Porto, Civilização.

ZimMERMANN, M. (1989-1990): "Glose, tautologie ou inventaire? L'énumeration descriptive dans la documentation catalane du $\mathrm{X}^{\mathrm{e}} \mathrm{me}$ au $\mathrm{XII}^{\mathrm{me}}$ siècle", Cahiers de linguistique hispanique médiévale, 14-15, pp. 328-334. 